\title{
Salutogenesis and Ayurveda: indications for public health management
}

\author{
Antonio Morandi • Carmen Tosto • \\ Paolo Roberti di Sarsina • Dacia Dalla Libera
}

Received: 31 August 2011 / Accepted: 2 November 2011 /Published online: 1 December 2011

(C) European Association for Predictive, Preventive and Personalised Medicine 2011

\begin{abstract}
Ayurveda, the ancient traditional medicine of India, defines health as a state of complete physical, mental and spiritual well-being. The focus of Ayurveda is on a predictive, preventive and personalized medicine. This is obtained through a low-cost personalized counseling about lifestyle measures (diet, activities, etc.), trying to involve the patient directly in the process of healing, increasing his self-awareness and good relationships with other people and nature. The approach of Ayurveda toward positive health shares its features with that of salutogenesis as described by Antonovsky. Prevention strategies pragmatically suggested by Ayurveda - including factors such as promotion of health education, individual awareness,
\end{abstract}

\author{
A. Morandi $(\bowtie) \cdot$ C. Tosto $\cdot$ D. Dalla Libera \\ Ayurvedic Point, \\ C.SO Sempione 63, \\ 20149 Milan, Italy \\ e-mail: dr.morandi@ayurvedicpoint.it \\ URL: www.ayurvedicpoint.it
}

A. Morandi • P. Roberti di Sarsina • D. Dalla Libera SSIMA, Italian Scientific Society for Ayurvedic Medicine,

C.SO Sempione 63,

20149 Milan, Italy

D. Dalla Libera

IRCCS San Raffaele, Department of Neurology,

Via Olgettina 48,

20132 Milan, Italy

P. Roberti di Sarsina

Expert for non-conventional medicine, High Council of Health, Ministry of Health,

Rome, Italy

P. Roberti di Sarsina

Observatory and Methods for Health, Department of Sociology

and Social Research, University of Milan-Bicocca,

Milan, Italy integration of spirituality and ethics in healthcare systemmay be applied in public health management, in order to improve perceived and objective life quality, promote healthy aging, limit drugs use (avoiding expensive sideeffects) and reduce chronic diseases social costs. Ayurveda has a universal-coverage, being person-centered and consequently intercultural.

Keywords Ayurveda $\cdot$ CAM $\cdot$ Salutogenesis $\cdot$ Predictive medicine $\cdot$ Preventive medicine $\cdot$ Personalized medicine

\section{Ayurveda and the concept of health as personalized, predictive medicine}

Tradition - whatever its nature or origin - is the distillation of experience and therefore memory itself. It is the only path to finding man's true nature, recovering what has been forgotten and understanding the meaning of life itself. As one of the world's most ancient traditions, Ayurveda (translated rom sanskrit "knowledge of duration of life"), the traditional medicine of India and first of all anthropological/traditional medical systems, emphasizes the necessity of a more person-centered, personalized approach in medicine [1-4]. The process of healing has to be based on people's whole bio-psycho-spiritual unity and equilibrium, including their relation to the environment and the way they perceive or "narrate" their own complex individual existence, both in sickness and health. In Ayurveda the determinants of health are biological, ecological, medical, psychological, sociocultural, spiritual and metaphysical factors, all interdependent and wired together by the common concept of relationship. The harmonization and integration of these determinants in a complex system allows the emergence of what is identified as health. 
Individuals interact with the environment through the five senses. Perceptions are generated, processed and integrated into associative memories in a complex model of reality. This model enables the individual to adequately interact both with the received stimuli and with environment. According to Ayurveda these relationships determine the psychological structure, psycho-physical health and general balance of each organism. Health is a positive state and it is the outcome of the adaptive feedback that each being establishes with the environment. In human terms, health is not merely a biological process, it is also a cultural one involving knowledge as well as the interaction with the environment in order to modify it [5].

Ayurveda uses an analogical, associative logic to evaluate events. It does not use linear schemes, since they are not able to depict the complexity of reality. Ayurveda's focus is on relationships - regarded as determining events and not on objects. In fact, the process of observation is not static but dynamic, and seeks to identify coherent structures and shapes via a continuous flow of information. This approach is more suitable to explain events and structures, disentangling the complex multifaceted net of nature [6]. A similar relationship-based approach has emerged from the most recent discoveries and theories of modern Western science in quantum physics [7], the mathematics of chaos [8] and epigenetics [9-11].

The Ayurvedic model of reality is a network of information transmitted through material or virtual channels called srotas $[1,12,13]$. The meaning of the word srotas extends beyond a simple channel, duct or circulation of organic fluids: it connotes the interrelation between two points and therefore refers to information, energy, thoughts and feelings. A srotas can have different dimensions and characteristics: it can be a structured channel -such as a blood vessel or an intestinal tract-but also a functional channel- such as a membrane channel- a biochemical process or just a flow of information. Srotas, or relationships, form a network of knowledge that flows both within an organism and between that organism and its environment, forming an interactive mesh of intelligence that defines a living being moment by moment. Consequently, Ayurveda views an organism not merely as a system of organs, but as a system of relationships determining roles, forms and functions of the organs themselves. For instance, srotas determine the shape of the heart for an organism. If cardiac tissue is placed in vitro and allowed to grow, the result will not be a complete and functioning organ, but rather a mass of disconnected myocardial cells. This happens because in vitro relationships are different and lack the essential information able to determine shape and function as in living beings. The same is true for an organism in a particular environment, where the senses are responsible for transmitting information from perceptions: the srotas/relationships are the real determiners of the shape, function and reality we perceive. Thus, according on relationships we may predict different kind of manifestation of disease and better prevent them in a timely fashion. Ayurveda has a unique preventive and predictive role.

The Ayurvedic view extends the concept of relationships at molecular, atomic and subatomic levels, confirming the philosophical idea of the existence of deep connections between microcosm and macrocosm. The srotas/relationship is a substratum, which - like waves - allows basic material to convert into elements. As the environment shapes our minds and bodies, we are also able to influence and modify the environment. Life is a continuous, recursive action of self-affirmative perception and health evolves from the awareness and the equilibrium of our interaction with the environment.

The community itself is a system of relationships that determine the form, function and role of all individuals, and, therefore, individual social identity.

The concepts of srotas and the observation process, (i.e. the dynamic relationship that links the observer and the observed), correspond to quantum physics as stated in Heisenberg's uncertainty principle. The simplicity of Ayurveda's description of life parallels the simplicity of physics' description of the basic laws of nature, and Ayurveda yields a new way to comprehend quantum physics' observations of health, disease, social and environmental organization. Ayurveda's representation of the most important, primal and complex events is at the same time simple and elegant and absolutely precise. Ayurveda goes into deep, revealing the inner coherence of the system through observation.

Nature itself is simple in its essence yet complex in the matrix of life. A molecule is a complex entity formed by atoms composed of protons, neutrons and electrons, and they, in turn, are made of elementary particles. The mathematical complexity of defining every single component is immeasurable, but the general properties of a molecule drawn from the relationships between single elements are more easily found and described in real physical terms. It has been said, "A molecule of water does not explain a wave, but the relationship between molecules forms a wave" [14].

As the seven musical notes of the scale offer infinite melodies and four DNA bases generate countless shapes and manifestations of life, the three Doshas, the functional principles of life in Ayurveda, create and allow to describe every manifestation of nature. The three doshas are the subtle principle governing the physiological activities of the body. The 3-fold-classification (tridosha theory) identifies principles of motion (Vata), transformation (Pitta) and cohesion (Kapha) as discrete phenotypic groupings, as it is also verifiable through genetics $[2,15,16]$. 
Ayurveda describes health as swastha, a sanskrit term meaning "stability in the true self", a state of complete, balanced, physical, mental and spiritual well-being $[17,18]$. This remind us to United Nations' World Health Organization's definition of health (1948) as "a state of complete physical, mental, and social well-being and not merely the absence of disease or infirmity" [19].

The person-centered point of view of Ayurveda mainly concerns maintenance of an abiding health, preventing rather than treating diseases. If our health is compromised, the treatment resides in restoring the balance between the affected functions, the tissues, the environment and the whole organism. The nature of the individual is a parameter on which the whole system's scale is tuned.

The ayurvedic diagnosis process is based on the definition of the inborn constitutional health state of the patient (termed Prakriti in Sanskrit). The biomedical validity of constitutional assessment in Ayurveda has recently received confirmations from genomic studies. $[14,20-25]$. Health is an individual, relative state and prakrti may explain why peculiar diseases occurs to patient and not to another one. The determination of Prakriti - which consider psycho-physical attitudes and sociocultural circumstances - allows to define how the individual can achieve health. Through prakrti assessment we define what is Satmya (adequate, etimologically "making similar, homologous") or Asatmya (not adequate) for the organism [26]. Ayurveda promotes a model of positive health, thinking, feelings and general state of being. Ayurveda agrees with health as part of a regulatory inner system, so that each individual constitution represents what is adequate, an ideal, a simmetric, coherent collection of elements in a right order. The patient needs to follow his personal guidelines in order to achieve and maintain his ideal healthy state. Instead, disease, being a distortion from an ideal and inner order, a trait of entropy, is self-limiting, and it implies that the regulating system is not correctly functioning as expected.

According to Ayurveda, even the social system can be seen as a system of relationships, which defines the individuals in shape, function and role, consequently we may not define individual health without considering all the physical, psychical, spiritual and social parameters and relations. In this regard Ayurveda's approach to health might evoke also the Salutogenesis concept $[27,28]$ - as defined by Antonovsky, whose core issues such as Generalised Resistance Resources (GRRs) and Sense of Coherence (SoC) are to be naturally found in the Prakriti assessment and diagnostic process of Ayurveda. In fact the GRRs - the biological, material and psychosocial factors which let the people perceive their lives as structured and understandable - are explored during an ayurvedic visit through a deep and articulated colloquium with the patient aimed to obtain a complete vision of his/her psycho-social dimension and relationships. This will constitute one of the basis to determine the Prakriti or constitution of the patient. We need to consider not only the objective world of health but also the subjective one, since the latter is also part of the process of healing. In fact, the SoC, which is the way in which the individual perceive his/her life and abilities to success and cope with the complexity of life are also explored during this colloquium and often it constitute the target of the therapy. In Ayurveda one of the task of the doctor is to elicit the awareness of one's capacities and possibilities in order to pursue the individual optimal health. Ayurveda and Salutogenesis are both intercultural and universally applicable beyond cultural or ethnical backgrounds. They share the aim of constructing a positive health, in which the presence of disability does not exclude a state of well-being. In fact the patient, on the basis of his ability in pursuing personal goals and cultivating his knowledge, abilities and awareness, may overtake the obstacles related to feeling diseased.

But Ayurveda is an even more complex scientific and philosophical model of reality which accounts for its multidimensional preventive, health promotive and curative approach, and is able to give a wider spectrum of possible interventions and possibilities.

Moreover, health for Ayurveda is not a constant state of well being, it is rather an ideal space around an ideal condition in which the physiology can float around, the bigger the space the healthier the individual. The crossing of the boundaries of this space towards disorder is what is called diseased state, but the strength of an organism lies in the ability to return back to his overall ideal condition. The role of Ayurveda is to keep this space as wider as possible and to facilitate the return in case of a disease.

\section{Ayurveda and public health for preventive medicine}

The aim of this paper is not to discuss on the three types of health system described by WHO in which traditional medicine is officially acknowledged [29] (WHO traditional medicine strategy 2002-2005) and their eventually further implementation, rather to stress some methodological and philosophical issues pertaining to Ayurveda that can elicit some considerations on public health management. The comprehensive health concept of Ayurveda is in good accordance to what Winslow claimed in 1920 defining public health as "the science and art of preventing disease, prolonging life and promoting health through the organized efforts and informed choices of society, public and private organizations, communities and individuals" [30]. The aims of Ayurveda are shared by the focus of an ideal public health intervention. First, we need to prevent and then manage 
diseases and other health conditions: this is possible through surveillance, promotion of healthy behaviors and relationships inside communities as well as between human and environments. Instead, the present connotation of public health is mainly related to the social and health problems emerged from the industrial revolution of 19th century, acquiring from this "modernity" the concept of standardization and of grand-scale action which brought to a progressive distance from actual reality and individual needs [27]. It is now clear that the the actual statistical and epidemiological methods are not adequate for an efficient prevention or intervention: the need of a personalized medicine is now definitely outstanding.

Today, besides the recovery of the sense of reality, one of the most urgent needs of public health is to find alternative strategies for prevention and management of chronic diseases which are going out of control (issue brought on by 2011 UN General Assembly) [30-32]. This may be achieved, according to Ayurveda, through "swasthavritta", a low-cost-regimen of personalized healthy conduct fitted to the individual, involving lifestyle, nutrition, selfawareness and good relationships with other people and nature. For instance, we may think that many diseases are preventable through simple, non-medical methods since childhood, thanks to health education and social aid in personal self-realization. It is necessary to build a framework that support patients' and family interactions at the micro-level and a well-coordinated policy and healthcare systems, with attention to social and environmental aspects [33]. In fact, relationships between individuals in turn define individual themselves, contributing to awareness and self-realization and consequently, to the sense of well-being within communities [34]. This is also in agreement with the salutogenic approach stated in the Ottawa Charter of 1986: 'Health promotion is the process which enables people to gain control over their health determinants in order to improve their health and thereby be able to live an active and productive life' (WHO, 1986) [35].

Health can not prescind from individual perception of well-being and capacity to participate in social system. Ayurveda considers as determinants of happy and healthy life, experiences of meaning and wellbeing perception derived by one's contribution to personal, family or social material, psychological or spiritual activities. Thus, health status in general and mental health in particular, are the outcome of the adaptive feedback that each being establishes with the environment. Recently, Western medicine has begun to investigate with interesting findings what Ayurveda has considered for millennia: the effect of emotions on health [36-38]. Ayurveda places great attention on patient's mind-body relationship and considers mind as integral and inseparable part of the living being $[39,40]$. Body, mind and soul are diverse interrelating and interacting stages of the same system. Behavior and emotions need to be maintained in balance for health achievement. Ayurveda leads people to know their own nature, to adequately use the mind, and to modify the interactions with the environment in order to achieve an optimal status of health.

Relationships are a fundamental determinant of equilibrium and consequently of health according to Ayurveda. The social model of Ayurveda is strictly connected with the status of the individuals, and it could be defined as adaptive and recursive, resulting from the dynamic interactions existing within and between the individuals and the environment. Thus, the management of environment is of utmost importance in the health maintenance. As a matter of fact, the balance of the elements composing the surrounding of a living being influences its personal and social behavior, eventually defining its psychology and mental health. This is why Ayurveda stress the point on individual awareness as key factor in individual and social health. Awareness has a variety of diverse implications in health, from purely physical to spiritual. Ayurveda stress the achievement of the awareness from individuals of being part of a system, not to be just outsider observers. A complex system like social health arise out as an emergent behavior of multiple simple interactions between individuals' awareness.

The concept of awareness is effectively described by the mechanism of perception summarized by the concept of rishi-devata-chandas, in which the observer (rishi) is tied to the observed (chandas) by the inherent process of observation (devata), forming one single unit. This view is close to the recent description of the process of observation made in quantum mechanics, where observer and observed mutually interact and change $[8,41]$. This leads to an "ecologicallygrounded perception" and conception of life, where microcosm an macrocosm are strictly connected.

It could be summarized that the social health model of Ayurveda is directed bottom up, from individual to population. It takes into account not only factors strictly bearing medicality and prevention related to an ideal of the general population, but rather placing utmost attention to what are the one's perspectives and perception on what means to be healthy in specific social contexts. This involve attention to social, cultural, motivational and spiritual life of all the individuals. It is not coincidence that the Institute of Medicine in USA stressed the necessity to find a coherent health concept for the education of health profession of $21 \mathrm{st}$ century [42].

\section{Ayurveda and prevention for better, healthful aging}

The Charaka Samhita, one of the most important ayurvedic medical text dating back more than 2500 years but still 
currently used by ayurvedic medical community, opens with the chapter "The quest for longevity" [26]. Ayurveda concerns mostly with longevity, whose notion is not only limited merely to long-lasting life, but it encompasses all the conditions to live in health and vitality in order to achieve an healthy death, meaning the natural final experience of the cycle of life. Thus, in Ayurveda the concept of public health, even encompassing all ages, focuses primarily on the individual capability of healthy aging intended as complete fulfilling one's life [43, 44]. Thus, respecting healthy aging will not only prevent diseases but will reduce chronic conditions of elderly. The salutogenesis approach has already been used in Spain for promoting mental health in older people (as organized by the European Commission Directorate-General for health and Consumers and the Spanish Ministry of Health and Social Affairs with support of the Spanish Presidency of the European Union). Authors suggest a number of psychological resources for successful aging which include a positive outlook and self-worth, self-efficacy and a sense of control over life. Particularly important are how people can learn to cope with naturally changeable reality and situations. Successful ageing is an ever-changing and developing process over the life course, where people are required to retrain their ability to learn by using past experiences to cope with present circumstances. In a global world, characterized by rapid social changes, the ability to manage stress related to changes is crucial for the maintenance and development of health and quality of life. Ayurveda provides valid and practical instruments for manage and coping with stress. An example comes from the study on Abhyanga, an ayurvedic tecnique of total body massage with medicated oils, in anxiety and depression [45]. Thus, Ayurveda may be perfect as integration to conventional medicine for geriatrics, reducing the costs of visit and access to hospital by unsatisfied, lonely elderly patients not more able to face their daily life. Furthermore, the peculiar Ayurvedic health assessment approach - through individual constitution determination which considers body, mind, behavior, environment, spiritual attitude- may lead to more efficacious strategies of prevention that will improve life quality, limit drugs use (avoiding expensive side-effects) and reduce chronic diseases social costs. If we early predict the dynamic imbalance possibly leading to disease in the single patient, we will be able to better prevent chronic, mostly static incurable condition. At the same time, investigating on all aspect of life (even cultural, familiar and spiritual facets) we will be able to identify the best remedies for each patient.

There is an evident and increased need of integration of spirituality in healthcare systems [46-50]. Many indicators address also in this direction, the WHO debate whether adding the spiritual dimension to the definition of health
[51], the Copenhagen Declaration on Social Development signed by all nations at the World Summit for Social Development in which they acknowledge that the society must respond to the spiritual needs of their populations, and commit themselves to orient their policies towards a 'political, economic, ethical, and spiritual vision for social development' [52], and recently the The Bangkok Charter for Health Promotion in a Globalized World in which the United Nations define health as a determinant of the quality of life and encompassing mental and spiritual well-being [53]. In Western world the concept of spirituality is often related and sometime confused with religion, instead of a value related to the capacity to contact and experience the deepest values and meanings by which people live [54]. People use spirituality as a resource to enhance their psychological and emotional wellbeing in order to reach an higher level of Quality of Life as well as psychophysical health. It is thus of utmost importance that public health management promote health education and integrate spirituality and ethics in healthcare system since early ages and integrate spirituality and ethics in healthcare system [55] as announced by the 2012 WHO health report "stimulating the generation, translation and dissemination of valuable knowledge" [56].

Since macrocosm and microcosm are in constant interactions, and relationships between individuals in turn define the individual themselves, an healthy being will ultimately lead to an healthy, happy society. It has recently demonstrated that the way people view their life has a positive influence on their health [57]. Moreover Delle Fave and Massimini demonstrated that the association of optimal experiences and skill cultivation with structured and long-term meaningful activities could be used as an intervention tool for the promotion of individual development and social integration [58] in youth and adults.

Ayurveda is a traditional healthcare system affording creation of positive health and enforcing total quality life issues. Moreover, public health needs to foster patients inner "Sense of Coherence", to promote long term mental health. With this aim, Ayurveda is concerned on developing meaningful relationships between community members and public health practitioners. As stated by Charaka Samhita Sutrasthana 9: 26 - one of the main Ayurvedic textbook "a doctor should be sympathetic and kind to all patients" [26], he must consider each individual's perception of the world, inner "sense of coherence" and mind-body interactions. Communication should be improved and patient involvement enhanced, so that people are made responsible for their own health. The role of the professionals is to support and provide options that enable people to make their proper choices, to make people aware. If the physician is able to show the patient - confused by his diseased condition- the most common and evident conditions of life 
such as individual nature and habits, seasons, climate and so on, he will drive the patient himself toward an increased degree of awareness and personal responsibility. The role of doctors in public health is basically a cultural one (instead of being a member of technical elite unreachable in its means by common people, that are scared by their ignorance of nature and its cycle). Knowledge is the main factor necessary to achieve optimal health. Deep comprehension of one's nature leads to the adoption of life style and habits that support one's possibilities. Ignorance conducts to practices and customs which are not suitable with one's constitutions, exiting in unbalances, maintenance of diseases and unhealthy death. Health is self generated by equilibrium and balance in the behavior of individuals at every level. This is the real meaning of health promotion on public health according to Ayurveda. Many diseases may be preventable through simple, non-medical methods (diet, meditation, massage) since infancy, in order to improve life quality, limit drugs use (avoiding expensive side-effects) and reduce medical costs. Ayurveda's suggestions on Doctor-Patient relationship and in the management of mood disorders may be of great help [59].

\section{Conclusions}

Ayurveda, the traditional medicine of India, is a personalized medicine whose principle is based on patient individual constitution (prakrti) and relationships. Its focuses are a predictive, preventive medicine, a well-respected concepts in modern molecular medicine. Thus, we propose that Ayurveda and Western medicine may be tunefully integrated with reciprocal benefit. Finally Ayurveda is based on universal principles - not limited to a particular ethnic group or culturebeing both person-centered and intercultural and it can be used as an integration of the existent healthcare systems as well as a template to rescue local traditional values in order to meet the needs of different populations.

\section{References}

1. Morandi A, Tosto C, Sartori G, Roberti di Sarsina P. Advent of a Link between Ayurveda and Modern Health Science: The Proceedings of the First International Congress on Ayurveda, "Ayurveda: The Meaning of Life-Awareness, Environment, and health" March 21-22, 2009, Milan, Italy. Evid Based Complement Alternat Med. 2011;2011:929083.

2. Hankey A. The scientific value of Ayurveda. J Altern Complement Med. 2005;11(2):221-5.

3. Cooper EL. Ayurveda and eCAM: A closer connection. Evid Based Complement Alternat Med. 2008;5(2):121-2.

4. Bodeker G. Evaluating Ayurveda. J Altern Complement Med. 2001;7(5):389-92.
5. Kovacs J. Concepts of health and disease. J Med Philos. 1989;14 (3):261-7.

6. Hankey A. Are we close to a theory of energy medicine. J Altern Complement Med. 2004;10(1):83-6.

7. Bell JS. Speakable and unspeakable in quantum Mechanics. 1966 reprint 1987, Cambridge: Cambridge University Press.

8. Strogatz S. Exploring complex networks. Nature. 2001;410:268-76.

9. Rodriguez-Rodero S, Fernández-Morera JL, Fernandez AF, Menéndez-Torre E, Fraga MF. Epigenetic regulation of aging. Discov Med. 2010;10(52):225-33.

10. Feinberg AP. Epigenetics at the epicenter of modern medicine. JAMA. 2008;299(11):1345-50.

11. Feinberg AP. Phenotypic plasticity and the epigenetics of human disease. Nature. 2007;447(7143):433-40.

12. Singh RH. Exploring issues in the development of Ayurvedic research methodology. J Ayurveda Integr Med. 2010;1:91-5.

13. Singh RH. Exploring quantum logic in Ayurveda with special reference to Srotovijnan of Ayurveda. AYU. 2009;30:360-8.

14. Patwardhan B, Bodeker G. Ayurvedic genomics: establishing a genetic basis for mind-body typologies. J Altern Complement Med. 2008;14(5):571-6.

15. Hankey A. A test of the systems analysis underlying the scientific theory of Ayurveda's Tridosha. J Altern Complement Med. 2005;11(3):385-90.

16. Buchanan M. The Social Atom. New York: Bloomsbury Press; 2007.

17. Sharma H, Chandola HM, Singh G, Basisht G. Utilization of Ayurveda in health care: an approach for prevention, health promotion, and treatment of disease. Part 1-Ayurveda, the science of life. J Altern Complement Med. 2007;13(9):1011-9.

18. Sharma H, Chandola HM, Singh G, Basisht G. Utilization of Ayurveda in health care: an approach for prevention, health promotion, and treatment of disease. Part 2-Ayurveda in primary health care. J Altern Complement Med. 2007;13(10):1135-50.

19. Constitution of the World Health Organization. Am J Public Health Nations Health. 1946;36(11):1315-23.

20. Aggarwal S, Negi S, Jha P, Singh PK, Stobdan T, Pasha MA, et al. EGLN1 involvement in high-altitude adaptation revealed through genetic analysis of extreme constitution types defined in Ayurveda. Proc Natl Acad Sci USA. 2010;107:18961-6

21. Bhushan P, Kalpana J, Arvind C. Classification of human population based on HLA gene polymorphism and the concept of Prakriti in Ayurveda. J Altern Complement Med. 2005;11 (2):349-53.

22. Ghodke Y, Joshi K, Patwardhan B. Traditional Medicine to Modern Pharmacogenomics: Ayurveda Prakriti Type and CYP2C19 Gene Polymorphism Associated with the Metabolic Variability. Evid Based Complement Alternat Med. 2009. doi:10.1093/ecam/nep206.

23. Prasher B, Negi S, Aggarwal S, Mandal AK, Sethi TP, Deshmukh $\mathrm{SR}$, et al. Whole genome expression and biochemical correlates of extreme constitutional types defined in Ayurveda. J Transl Med. 2008;6:48.

24. Rizzo-Sierra CV. Ayurvedic genomics, constitutional psychology, and endocrinology: the missing connection. J Altern Complement Med. 2011;17:465-8.

25. Tripathi PK, Patwardhan K, Singh G. The basic cardiovascular responses to postural changes, exercise, and cold pressor test: do they vary in accordance with the dual constitutional types of ayurveda? Evid Based Complement Alternat Med. 2011. doi:10.1155/2011/251850.

26. Charaka Samhita. Dash B, Sharma RK. Varanasi: Chowkhamba Sanscrit Series Office; 1983.

27. Lindstrom B, Eriksson M. Contextualizing salutogenesis and Antonovsky in public health development. Health Promot Int. 2006;21(3):238-44. 
28. Lindstrom B, Eriksson M. Salutogenesis. J Epidemiol Community Health. 2005;59(6):440-2.

29. Jekel JF. Health departments in the U.S. 1920-1988: statements of mission with special reference to the role of C.E.A. Winslow. Yale J Biol Med. 1991;5(64):467-79.

30. Roberti di Sarsina P. The Social Demand for a Medicine Focused on the Person: The Contribution of CAM to healthcare and healthgenesis. Evid Based Complement Alternat Med. 2007;4 (Supp1):45-51.

31. Allotey P, Reidpath DD, Yasin S, Chan CK, de-Graft Aikins A. Rethinking health-care systems: a focus on chronicity. Lancet. 2011;377:450-1.

32. Geneau R, Stuckler D, Stachenko S, McKee M, Ebrahim S, Basu S, et al. Raising the priority of preventing chronic diseases: a political process. Lancet. 2010;376:1689-98.

33. Gadgil VD. Understanding ayurveda. J Ayurveda Integr Med. 2010;1:77-80.

34. Schultz AM, Chao S, McGinnis JM. Integrative medicine and the health of the public: a summary of the February 2009 summit. Washington: National Academies Press; 2009.

35. World Health Organization: The Ottawa Charter for Health Promotion. 1986; Available from: http://www.who.int/healthpromotion/ conferences/previous/ottawa/en/.

36. Wiest M, Schüz B, Webster N, Wurm S. Subjective well-being and mortality revisited: Differential effects of cognitive and emotional facets of well-being on mortality. Health Psychol. 2011;30:728-35.

37. Ostir GV, Markides KS, Peek MK, Goodwin JS. The association between emotional well-being and the incidence of stroke in older adults. Psychosom Med. 2001;63(2):210-5.

38. Brummett BH, Boyle SH, Kuhn CM, Siegler IC, Williams RB. Positive affect is associated with cardiovascular reactivity, norepinephrine level, and morning rise in salivary cortisol. Psychophysiology. 2009;46(4):862-9.

39. Obeyesekere G. The theory and practice of psychological medicine in the Ayurvedic tradition. Cult Med Psychiatry. 1977;1(2):155-81.

40. Rao AV. Mind in ayurveda. Indian J Psychiatry. 2002;44(3):201-11.

41. Penrose R. The Emperor's New Mind: Concerning Computers, Minds, and the Laws of Physics. Oxford: Oxford University Press; 1989.

42. Beaglehole R, Bonita R. Global public health: a new era. Oxford: Oxford University Press; 2003.
43. Ventegodt S, Omar H, Merrick J. Quality of life as medicine: Interventions that induce salutogenesis. A review of the literature. Soc Indic Res. 2011;100:415-33.

44. Eriksson M, Lindstrom B. Antonovsky's sense of coherence scale and its relation with quality of life: a systematic review. J Epidemiol Community Health. 2007;61(11):938-44.

45. Basler AJ. Pilot study investigating the effects of Ayurvedic abhyanga massage on subjective stress experience. J Altern Complement Med. 2011;17(5):435-40.

46. Vader JP. Spiritual health: the next frontier. Eur J Public Health. 2006;16(5):457.

47. Treloar LL. Integration of spirituality into health care practice by nurse practitioners. J Am Acad Nurse Pract. 2000;12(7):280-5.

48. Thoresen CE, Harris AH. Spirituality and health: what's the evidence and what's needed? Ann Behav Med. 2002; 24(1):3-13.

49. Seybold KS. Physiological mechanisms involved in religiosity/ spirituality and health. J Behav Med. 2007;30(4):303-9.

50. Puchalski C. Spirituality in health: the role of spirituality in critical care. Crit Care Clin. 2004;20(3):487-504.

51. Spiritual health is important, say our readers. WHO Chron. 1979;33:29-30.

52. World Health Organization: Copenhagen Declaration on Social Development. 1995; Available from: www.un.org/documents/ga/ conf166/aconf166-9.htm.

53. World Health Organization, The Bangkok Charter for Health Promotion in a Globalized World. 2005; Available from: http://www. who.int/healthpromotion/conferences/6gchp/bangkok charter/en/.

54. Sheldrake P. A Brief History of Spirituality. Wiley-Blackwell; 2007.

55. Burr W. WHO moves to classify traditional medicines. CMAJ. 2011;183:E73-4.

56. World Health Report 2012 - No Health Without Research. 2011; Available from: http://www.who.int/rpc/whr2012/en/index.html.

57. Keyes CL. Promoting and protecting mental health as flourishing: a complementary strategy for improving national mental health. Am Psychol. 2007;62(2):95-108.

58. Massimini F, Delle Fave A. The Investigation of Optimal Experience and Apathy: Developmental and Psychosocial Implications. Eur Psychol. 2005;10(4):264-74.

59. Roberti di Sarsina P, Iseppato I. Why we need integrative medicine. EPMA J. 2011;2:5-7. 